
Not for reproduction, distribution or commercial use.

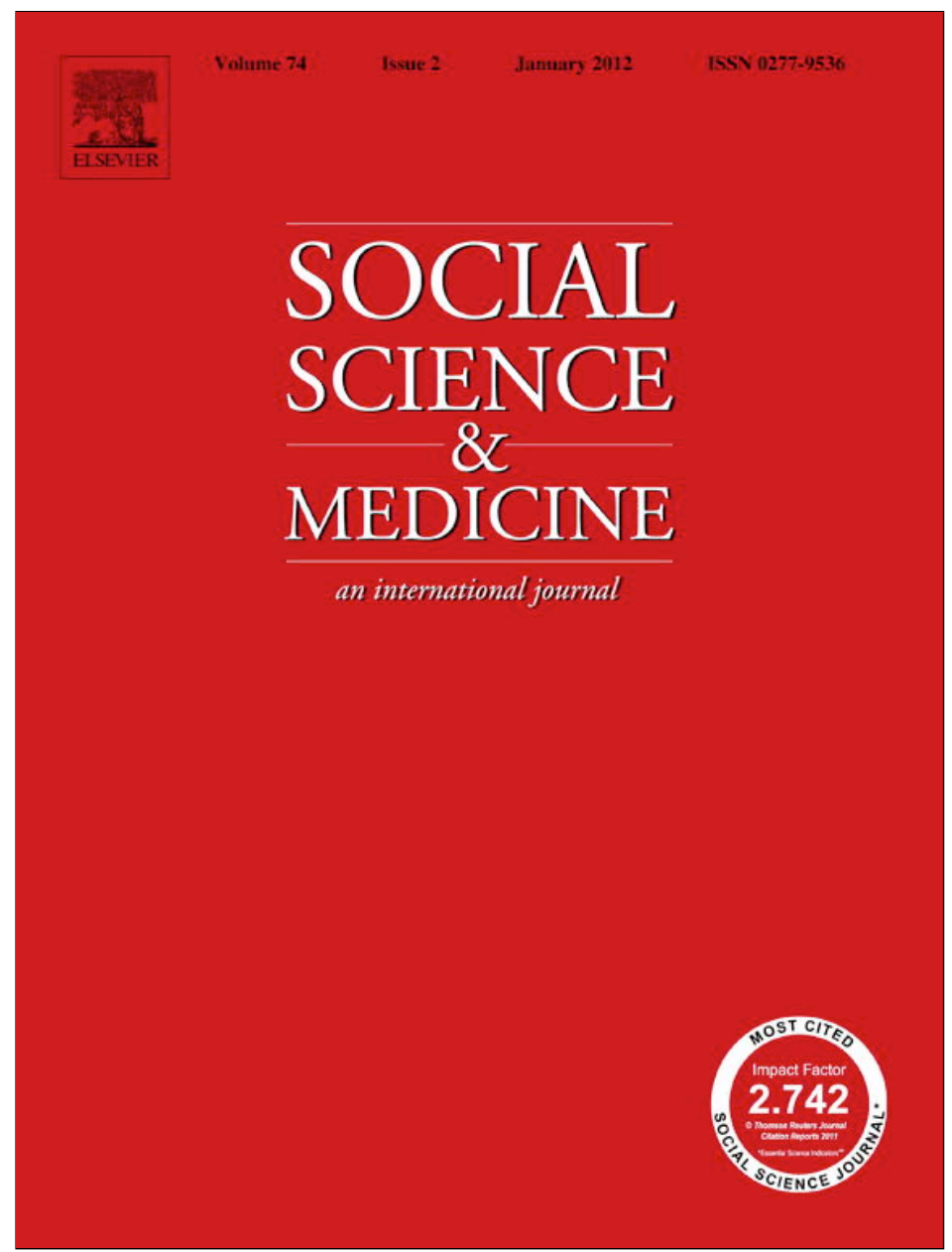

This article appeared in a journal published by Elsevier. The attached copy is furnished to the author for internal non-commercial research and education use, including for instruction at the authors institution and sharing with colleagues.

Other uses, including reproduction and distribution, or selling or licensing copies, or posting to personal, institutional or third party websites are prohibited.

In most cases authors are permitted to post their version of the article (e.g. in Word or Tex form) to their personal website or institutional repository. Authors requiring further information regarding Elsevier's archiving and manuscript policies are encouraged to visit:

http://www.elsevier.com/copyright 


\title{
Social capital and social inequality in adolescents' health in 601 Flemish communities: A multilevel analysis
}

\author{
B. De Clercq ${ }^{a, *}, V$. Vyncke ${ }^{a}$, A. Hublet ${ }^{a}$, F.J. Elgar ${ }^{b}$, U. Ravens-Sieberer $^{c}$, C. Currie $^{d}$, M. Hooghe ${ }^{e}$, A. Ieven ${ }^{f}$, \\ L. Maes ${ }^{\mathrm{a}}$ \\ ${ }^{a}$ Department of Public Health, University Hospital, Ghent University, Block A, De Pintelaan 185, 9000 Gent, Belgium \\ ${ }^{\mathrm{b}}$ Institute for Health and Social Policy \& Department of Psychiatry, McGill University, 1130 Pine Avenue West Montreal, Quebec, Canada \\ ${ }^{\mathrm{c}}$ Research Unit Child Public Health, University Medical Center Hamburg-Eppendorf, University of Hamburg, Martinistr. 52, 20246 Hamburg, Germany \\ ${ }^{\mathrm{d}}$ Child and Adolescent Health Research Unit (CAHRU) Medical School, University of St Andrews, North Haugh, St Andrews KY16 9TF, UK \\ ${ }^{\mathrm{e}}$ Centre for Political Research, Leuven University, Parkstraat 45 - bus 3602, 3000 Leuven, Belgium \\ ${ }_{\mathrm{f}}^{\mathrm{f}}$ EuroHealthNet, Rue de la loi 67, 1040 Brussel, Belgium
}

\section{A R T I C L E I N F O}

\section{Article history:}

Available online 3 December 2011

\section{Keywords:}

Belgium

Health promotion

Youth

Social gradient

Social capital

Inequalities

Neighborhoods

\begin{abstract}
A B S T R A C T
Although it is widely acknowledged that community social capital plays an important role in young people's health, there is limited evidence on the effect of community social capital on the social gradient in child and adolescent health. Using data from the 2005-2006 Flemish (Belgium) Health Behavior among School-aged Children survey (601 communities, $n=10,915$ ), this study investigated whether community social capital is an independent determinant of adolescents' perceived health and well-being after taking account of individual compositional characteristics (e.g. the gender composition within a certain community). Multilevel statistical procedures were used to estimate neighborhood effects while controlling for individual level effects. Results show that individual level factors (such as family affluence and individual social capital) are positively related to perceived health and well-being and that community level social capital predicted health better than individual social capital. A significant complex interaction effect was found, such that the social gradient in perceived health and well-being (i.e. the slope of family affluence on health) was flattened in communities with a high level of community social capital. Furthermore it seems that socioeconomic status differences in perceived health and well-being substantially narrow in communities where a certain (average) level of community social capital is present. This should mean that individuals living in communities with a low level of community social capital especially benefit from an increase in community social capital. The paper substantiates the need to connect individual health to their meso socioeconomic context and this being intrinsically within a multilevel framework.
\end{abstract}

(C) 2011 Elsevier Ltd. All rights reserved.

\section{Introduction}

Promoting child and adolescent health is a key issue for public health policy. Traditionally, interventions have focused on proximal factors to improve health through behavioral change focused on individuals' knowledge, attitudes and skills, but this approach largely places responsibility on individuals and evaluation studies indicate that the effects are limited especially in disadvantaged populations (Marmot et al., 2010). The social ecological model of health (Stokols, 1996) emphasizes the dynamic interplay between

\footnotetext{
* Corresponding author. Tel.: +329 26494 02; fax: +32 92649410.

E-mail address: B.DeClercq@ugent.be (B. De Clercq).
}

situational and personal factors rather than focusing exclusively on environmental, biological, or behavioral determinants of health and well-being. Identical environmental conditions may affect people's health differently, depending on personal factors or perceptions of the environment. More recently, environmental strategies have shown more success (Frumkin, 2003), however most environmental interventions have addressed the physical environment ignoring the importance of the social environment. Therefore, distal factors like socioeconomic status and social capital open new perspectives to understand children's and adolescents' health and open new opportunities for interventions. Social capital research offers a way to enhance our understanding of the mechanisms through which support for the physical, emotional and social development of children and young people at key life stages can be achieved (Morgan \& Haglund, 2009). 
Health is a social product with strong societal roots (Wilkinson, 1996). Mechanisms that produce health and illness cannot be explained only by individual characteristics, but have to be investigated within a broader social context. The last twenty years have witnessed an explosion of interest in neighborhood or area effects on health (Diez Roux, 1998, 2001; Macintyre, Ellaway, \& Cummins, 2002; Pickett \& Pearl, 2001). Yet, the relationship between neighborhoods and health remains underexplored and calls for more careful analysis (Ellen, Mijanovich, \& Dillman, 2001). Children's and young people's health behaviors in particular are shaped not only by personal decisions of individuals by also by the routine organization of everyday settings (Mechanic, 1990).

\section{The social gradient in adolescents' health}

Health is not uniformly distributed throughout social systems. Health inequalities are well established in a number of studies in varied populations (Kawachi, Subramanian, \& Almeida-Filho, 2002; Marmot, Friel, Bell, Houweling, \& Taylor, 2008; Subramanian \& Kawachi, 2004; Wilkinson, 1996). Socioeconomic status (SES) is inversely associated with the prevalence of health complaints: the so-called gradient in health (Adler et al., 1994; Marmot et al., 1991). Recent studies found that youth from less wealthy families are more likely to report being in poor health (Boyce, Davies, Gallupe, \& Shelley, 2008; Currie, Molcho et al., 2008; Morgan \& Haglund, 2009). On the community level, residents of socially and economically deprived communities experience worse health than those living in more prosperous communities (Ellen et al., 2001). Aneshensel and Sucoff (1996) found that adolescents living in low SES neighborhoods are significantly more likely to suffer from depression, anxiety, conduct disorder and oppositional defiant disorder. This study also found that depressive symptoms negatively related to perceived social cohesion in the neighborhood. Therefore, research into the health of young people should consider both an individual's socioeconomic position and the socioeconomic and demographic environment in which they live. A common theory of the association between income inequality and health is that widening income differences reduces social capital and thereby negatively affects social supports and connections that promote health (Kawachi, Kennedy, Lochner, \& Prothow-Stith, 1997; Pearce \& Davey Smith, 2003; Wilkinson, 1996). The present study focuses on social capital as a mechanism to explain inequalities in health and more precisely the effect of community social capital on the social gradient in health.

\section{The protective role of community social capital}

Communities are important for physical and mental health and well-being (Marmot et al., 2010). Recently researchers and policymakers have paid increasing attention to the concept of social capital as a major issue for public health (Baum, 1999; Lynch, Due, Muntaner, \& Davey Smith, 2000; Wilkinson, 2000). Despite the lack of consensus concerning its definition, two distinct conceptions of social capital can be distinguished (Kawachi, 2006). The "social cohesion" school conceptualizes social capital as the features - for example, trust, norms, and mutual assistance - available to members of social groups. Making the connection with individual health, the question remains whether a lonely retired man, living in a lively and socially cohesive community, will obtain health benefits from the community where he lives, bearing in mind his individual lack of social relations? The social cohesion school emphasizes so-called "contextual" influences exerted on the individuals who live within certain contexts. The "network" theory defines social capital as the resources - for example, instrumental support, information channels, social credentials - that are embedded within an individual's social networks (Lin, 1999). In contrast to the social cohesion school, the network approach conceptualizes social capital as an individual attribute as well as a property of the collective (Kawachi, Subramanian, \& Kim, 2008). The present study conceptualizes social capital in line with the social cohesion school as a collective characteristic of places arising from people's shared experiences. It can be defined as the quantity and quality of social relationships such as formal and informal social connections as well as norms of reciprocity and trust that exist in a place or a community (Kawachi \& Berkman, 2000). Comprehensive reviews of the extensive social capital literature can be found elsewhere (Portes, 1998, 2000), and some specifically relating to health (Hawe \& Schiell, 2000; Macinko \& Starfield, 2001).

The relationship between social capital and health has mainly been studied in US research on adult health (Waterson, Alperstein, \& Stewart Brown, 2004). In the seminal work of Bourdieu (1986), Coleman (1988) and Putnam (1993), children do not feature prominently. Although most studies on social capital and health relate to adults (Hawe \& Schiell, 2000; Hemingway \& Marmot, 1999), some showed health effects in children (Scales, 1999). Social capital is a potential resource of resilience of poor health. Evidence suggests that social capital may impact children's wellbeing as early as the preschool years (Runyan et al., 1998). Specific evidence on community social capital and children's and adolescents' health remains limited. A number of studies have found beneficial effects of community level social capital on health (e.g. Folland, 2007; Subramanian, Kawachi, \& Kennedy, 2001; Ziersch, Baum, MacDougall, \& Putland, 2005). Only a few studies found positive effects of community social capital in adolescent populations (Boyce et al., 2008; Drukker, Kaplan, Feron, \& van Os, 2003). Morgan and Haglund (2009) found that adolescents with low neighborhood participation were almost twice as likely to report 'less than good health'. A number of studies demonstrate that various non-psychotic psychiatric disorders are associated with the quality of social networks and the social cohesion in a neighborhood, and this effect operates across the life cycle in children, adolescents and adults (Ellen et al., 2001). Fundamentally, social capital describes supportive, respectful relationships between community members resulting in a civil society (Waterson et al., 2004). These kinds of qualitative relationships could influence health by enhancing emotional well-being and reducing the stress generated by day-to-day life events. Social capital can be described as an 'external coping resource' that provides social support, information or resources. Neighborhoodbased social networks may shape health outcomes through communicating health-facilitating information, transmitting norms about accepted behaviors, and providing social support (Ellen et al., 2001).

\section{Community social capital: does it reduce health inequalities?}

Influential epidemiological studies (Berkman \& Syme, 1979; House, Landis, \& Umberson, 1988) emphasized the role of social relations as a moderator of health risk factors. Given the persistent inequalities that exist in adolescent health (Currie, Nic Gabhainn, et al., 2008), social capital is thought to act as a protective factor against poor outcomes (Morgan \& Ziglio, 2007). Kawachi et al., (1997), Kawachi, Kennedy, \& Glass (1999) were among the first researchers to empirically demonstrate the interrelationships between health inequalities and social capital at the contextual level. A Dutch study (van der Linden, Drukker, Gunther, Feron, \& van Os, 2003) showed that the negative effect of socioeconomic deprivation on mental health service use was stronger in neighborhoods with low community social capital. Waterson et al. 
(2004) also identified social capital as a key factor in explaining child health inequalities. In their review, Vyncke et al. (submitted for publication) conclude that community social capital influences the relation between socioeconomic characteristics and health outcomes in children and adolescents, although a greater number of European studies are needed in order to provide more substantive evidence for the European context. It also remains unclear what mechanisms precisely explain this link. The present study tries to fill this knowledge gap.

\section{Multilevel perspective}

Despite its popularity in political, economic and public health domains, the social capital concept remains to be fully defined and understood (Lynch, Due et al., 2000; Muntaner \& Lynch, 1998). One of the most important discussion points in the literature is the level of aggregation on which social capital has an influence in general (Portes, 2000), and specifically on health outcomes (Poortinga, 2006; Subramanian, Lochner, \& Kawachi, 2003). The present research contributes to this multilevel perspective by simultaneously investigating the effects of individual social capital and community social capital.

The reviewed literature has shown that a single level analysis, like the ecological and individual approaches, has its limitations. In an aggregate analysis, the variation in health within group A may be much larger than within group $B$ while both groups still have the same mean. Robinson (1950) demonstrated this problem of 'ecological or aggregation fallacy'. In the case of ecological studies, variations between different contexts could be due to contextual effects or differences in composition (Subramanian, Kim, \& Kawachi, 2002). Therefore, ecological data are open to either the individualist or collective interpretations of social capital (Kawachi, Kim, Coutts, \& Subramanian, 2004). On the other hand, an individualistic approach ignores the context within which individuals experience differential levels of health - the 'atomistic fallacy' (Macintyre, 2000). The atomistic fallacy arises because associations between two variables at the individual level may differ from associations between analogous variables measured at the group level (Diez Roux, 2002). Individual level analysis may therefore obscure very real contextual effects (Poortinga, 2006). It is highly important to be aware of this heterogeneity, both between individuals and between contexts, while investigating contextual effects on health. Between context and between individual heterogeneity can be investigated through the application of multilevel modeling (Diez Roux, 1998; Duncan, Jones, \& Moon, 1998; O'Campo, 2003). Recent social capital research confirms that the most appropriate study design and analytical approach for investigating contextual effects of community social capital is within a multilevel framework (Kawachi et al., 2004; Subramanian, 2004). Summarizing the theoretical and methodological background of the social capital concept, we claim that it is intrinsically multilevel.

\section{Research questions}

Using a multilevel theoretical and methodological approach (Kawachi et al., 2004; Subramanian, 2004; Subramanian, Jones, \& Duncan, 2003), our aim was to examine how social capital augments social gradients in children's health (Adler et al., 1994; Wilkinson, 1996). This study introduces the social capital mechanism into the relationship between individual socioeconomic position and perceived health. Furthermore this research also contributes to the need for European evidence on this subject (Vyncke et al., submitted for publication). Our questions were as follows: is social capital at the community level an independent determinant of adolescents' health after taking account of individual compositional characteristics (e.g. characteristics such as gender, age, socioeconomic status and individual social capital)? And more specifically, can community social capital level up the gradient in health?

\section{Methods}

Sample

The main data come from the 2005-2006 survey of Flemish Health Behavior among School-aged Children, which is part of the international Health Behaviour in School-Aged Children survey: a WHO Collaborative Cross-National Study (HBSC) (Currie et al., 2009). These are self-reported data collected from school children from the 5th year of primary school to the 4th year of secondary school. The survey was administrated through a standardized protocol (Roberts et al., 2007) and was approved by the ethic committee of the University hospital of Ghent (project EC UZG2005/383).

To provide more objective evidence on community effects, we strengthened these measures with data from the Social Cohesion Indicators Flanders database (SCIF) 2007-2011. These data are gathered at the community level (postal code) from several databases from the Federal Police, Social Security, the National Institute for Statistics, the Federal Government Department of Statistics and the Roman-Catholic Church. The theoretical and methodological framework of this database is discussed extensively elsewhere (Botterman, Hooghe, \& Reeskens, in press).

\section{Dependent variable}

Health was measured using a 10-item index of children's and adolescents' perceived health status and well-being. This nonclinical index, developed by the Kidscreen project, ensured cultural, legislative/political and personal acceptance in 13 European countries, which are representative for the majority of the countries already participating in the HBSC study (Erhart et al., 2009). It consists of 10 items with 5-point answer-categories: "Thinking about last week...Have you felt fit and well? Have you felt full of energy? Have you felt sad? Have you felt lonely? Have you had enough time for yourself? Have you been able to do the things that you want to do in your free time? Have your parent(s) treated you fairly? Have you had fun with your friends? Have you got on well at school? Have you been able to pay attention?" ( $0=$ never, $1=$ seldom, $2=$ quite often, $3=$ very often, $4=$ always $)$. The construct validity of the index was demonstrated extensively (Ravens-Sieberer et al., 2010). Also a good internal consistency reliability $(\alpha=0.82)$ and the good test-retest reliability $(r=0.73)$ enable a precise and stable measurement.

\section{Independent variables}

A multilevel model is only invariant for linear transformations if there are no random regression slopes. Because this is not the case for the current study, all independent variables were grand-mean centered so that the intercept is interpretable (Hox, 2002).

\section{Level 1}

The present study employs family affluence as an indicator for individual socioeconomic status (Currie, Elton, Todd, \& Platt, 1997). The family affluence scale is a composite indicator of self-reported socioeconomic status comprising four items that address family assets or conditions that indicate wealth: "Does your family own 
a car, van or truck? $(0=$ no; 1 = yes one; $2=$ yes two or more $)$; Do you have your own bedroom for yourself? $(0=$ no; $1=$ yes $)$; During the past 12 months, how many times did you travel away on holiday with your family? $(0=$ not at all, $1=$ once, $2=$ twice, 3 = more than twice); How many computers does your family own?" ( $0=$ none, $1=$ one, $2=$ two, $3=$ more than two). Responses are summed on a 1 to 10 scale with higher scores indicating greater affluence. From its early development, there have been efforts to validate the family affluence scale at both national and international levels (Currie, Molcho et al., 2008). There is a strong agreement between children's reports on family affluence scale items and their parents' report (Andersen et al., 2008).

Individual social capital is measured by the participation in clubs: "Are you involved in any of these kinds of clubs or organizations?" Response categories: sports club, voluntary service, political organization, cultural organization, cultural association, church or religious group, youth club, other club $(0=$ no, $1=$ yes $)$.

\section{Level 2}

Community social capital is measured using a 5-item scale (Currie, Samdal, Boyce, \& Smith, 2001): “People say 'hello' and often stop to talk to each other in the street; it is safe for younger children to play outside during the day; you can trust people around here; there are good places to spend your free time; I could ask for help or a favor from neighbours" ( 1 = strongly disagree, 2 = disagree, $3=$ neither agree nor disagree, $4=$ agree, $5=$ strongly agree). Cronbach's alpha was supporting internal reliability $(\alpha=0.73)$. A factor analysis is performed using SPSS 19 (SPSS for Windows, Rel. 19.0.0.1 2010. Chicago: SPSS Inc.). All items load on one factor (results available from the authors). It is legitimate to aggregate individual responses to obtain area-based measures of social capital thanks to the useful features of multilevel analysis (Kawachi et al., 2004).

Both objective community measures are derived from the Social Cohesion Indicators Flanders database. Analysis confirmed that the communities are representative for all communities within the Flemish region and that the sample of respondents $(n=2080)$ is representative for the population of that region as well (Botterman \& Hooghe, 2010). Average income is the level 2 equivalent of family affluence at the individual level. The "traditional social cohesion scale" consists of three items (Botterman et al., in press): property crimes, religious participation and voluntary associations. The theoretical basis of these items relates to the work of Sampson, Raudenbush, and Earls (1997) and Putnam (1993). The basic assumption is that in traditional communities with high levels of participation, crime rates tend to be lower.

\section{Analyses}

Multilevel modeling is employed using MLwiN software (version 2.10) to account for non-random clustering of individuals in communities (Hox, 2002; Rasbash, Steele, Browne, \& Goldstein, 2009). Models are calibrated using the Maximum Likelihood procedure which utilizes the (Restricted) Iterative Generalized Least Squares algorithm (Goldstein, 2003). Multilevel regression analysis estimates whether the community differences in health are due to the characteristics of the people who live in these communities (compositional variation in communities) or due to factors that relate to communities themselves (contextual variation in communities) (Subramanian et al., 2002). This statistical modeling framework allows estimation of (1) the effect of individual and community level predictors on health (fixed part), and (2) the variation between communities in health that cannot be accounted for by the included factors (random part). The model can be described by the following equation:
$Y_{\mathrm{ij}}=\beta_{0 \mathrm{j}}+\beta_{\mathrm{k}} X_{\mathrm{ki}}+\gamma_{1} Z_{1 \mathrm{j}}+\mu_{0 \mathrm{j}}+\mathrm{e}_{\mathrm{ij}}$

where $Y_{\mathrm{ij}}$ is the value of respondent $\mathrm{i}$ in community $\mathrm{j}$ on health $Y$, $\beta_{0 \mathrm{j}}$ the overall constant (intercept), $X_{\mathrm{ki}}$ the value of respondent $\mathrm{i}$ on level 1 predictor $x_{\mathrm{k}}, \beta_{\mathrm{k}}$ the effect of level 1 predictor $x_{\mathrm{k}}, Z_{\mathrm{lj}}$ the value of community $\mathrm{j}$ on level 2 predictor $Z_{\mathrm{lj}}, \gamma_{1}$ the effect of level 2 predictor $Z_{\mathrm{lj}}, \mu_{0 \mathrm{j}}$ the residual for community $\mathrm{j}$ and $e_{\mathrm{ij}}$ the residual for respondent $\mathrm{i}$ in community $\mathrm{j}$. The equation refers to a random slope model.

This paper adopts a similar multilevel approach to that of Subramanian et al. (2002) to examine whether social capital has a separate contextual effect on individual's health at the community level, after taking into account individual compositional differences in social capital. The essential difference between Subramanian et al.'s approach and ours is that the present paper includes different items on both levels to measure individual and community social capital instead of using an identical social capital scale on both levels. This statistical approach of analyzing social capital on two different levels resonates with social capital's (theoretically) assumed differential effect (e.g. Poortinga, 2006; Portes, 2000).

First, an intercept-only model is fitted, without any level 1 or level 2 predictors (Model 1). This model is useful as a null model that serves as a benchmark with which other models are compared (Hox, 2002). Model 2 includes the socio-demographic variables as covariates. Individual social capital and family affluence are added as explanatory variables in Model 3. This model estimates the contribution of individual level variables to health. Model 4a to Model 6 include predictors at the community level and therefore allow us to examine whether the community level explanatory variables explain between group variation in the dependent variable. Objective community measures for socioeconomic status and social capital are introduced in Model 4. Model 5a considers social capital at the community level, without controlling for individual social capital. The next step is to include social capital at the community level, as well as at the individual level (Model 5b). Together, model $5 \mathrm{a}$ and $5 \mathrm{~b}$, should be able to reveal a possible differential effect of individual and community social capital on health. A possible mediating pathway of community social capital on the relationship between family affluence and perceived health and well-being is tested by building up a stepwise model. By estimating different subsequent models, a possible change in the coefficient for family affluence was monitored. More specifically, the value of the coefficient for family affluence in Model 5b was compared to its value in Model 4. Model 5b is identical to Model 4 except for the parameter of community social capital. Models 1 to $5 \mathrm{~b}$ are all variance component models because only the regression intercept is assumed to vary across communities, while the regression slopes remain fixed. Modeling the random part, only the explanatory variables that have a significant slope variance component between the communities are added simultaneously in a final fully random model. The final model (Model 6) examines a cross-level interaction between social capital at the community level and family affluence at the individual level. Theoretically we consider an interaction effect of community social capital on the slope of family affluence and perceived health and well-being. A negative interaction would support the buffering effect of community social capital on the social gradient in health (Aiken \& West, 1996). The global chi-square test is used to test the improvement of fit for each model (Hox, 2002).

\section{Results}

Table 1 presents an overview of the data structure and sample descriptors. Respondents ( $n=10,915$ ) are between 9 and 18 years old (Mean $=15$ years) and both boys and girls are proportionally distributed in the overall sample. 
Table .1

Data definition and structure.

\begin{tabular}{|c|c|c|}
\hline \multicolumn{3}{|l|}{ Response } \\
\hline $\begin{array}{l}\text { Perceived health and } \\
\text { well-being }\end{array}$ & Mean (s.d.) $=3.87(0.60)$ & $\begin{array}{l}\text { Range }=1(=\text { never })-5 \\
(=\text { always })\end{array}$ \\
\hline \multicolumn{3}{|c|}{ Level 1: Individuals, $n=10,915$} \\
\hline Gender & Base: Boy $(n=5530,49.6 \%)$ & $\begin{array}{l}\text { Contrast: Girl } \\
(n=5567,49.9 \%)\end{array}$ \\
\hline Age (in years) & Mean $($ s.d. $)=15$ years $(2.44)$ & Range $=9-18$ years \\
\hline Family affluence & Mean (s.d.) $=6.58(1.79)$ & Range $=1-10$ \\
\hline $\begin{array}{l}\text { Individual social } \\
\text { capital }\end{array}$ & Mean $($ s.d. $)=1.21(1.01)$ & Range $=0-7$ \\
\hline \multicolumn{3}{|c|}{ Level 2: Communities, $n=601$} \\
\hline Average income & Mean (s.d.) $=5.87(1.69)$ & Range $=0.64-10$ \\
\hline $\begin{array}{l}\text { Traditional social } \\
\text { capital }\end{array}$ & Mean (s.d.) $=5.11(1.19)$ & Range $=0-10$ \\
\hline $\begin{array}{l}\text { Community social } \\
\text { capital }\end{array}$ & Mean $($ s.d. $)=3.79(0.63)$ & $\begin{array}{l}\text { Range }=1 \\
\text { (=strongly disagree)-5 } \\
\text { (=strongly agree) }\end{array}$ \\
\hline
\end{tabular}

Source: Flemish Health Behaviors among School-aged Children survey (HBSC) 2005 06, $(N=9773)$, Social Cohesion Indicators Flanders database (SCIF) 2007/11.

Table 2 presents the results of six successive multilevel models. The first model shows that $5.6 \%$ of the variance in perceived health and well-being is at the community level. The grand-mean is 3.844 (range 1-5). This is the average perceived health and well-being from all respondents $(n=10,915)$ within all communities $(n=601)$. The second model shows that the socio-demographic variables are significantly associated with people's perceived health: girls and older adolescents report lower levels of perceived health and well-being $(p<0.001)$. These variables act as covariates in the subsequent models to control for compositional differences in socio-demographics. The third model accounts for the individual predictors. We observe a significant social gradient in the relationship between socioeconomic position and perceived health. Not surprisingly, people's perceived health and well-being is positively related to family affluence $(p<0.01)$. Individual social capital is positively related to a person's perceived health. Being a member of one additional association increases one's perceived health and well-being with 0.018 units on a 1 to 5 scale $(p<0.05)$.
We now turn to the evolution of community variation while estimating these models. After taking into account the individual socio-demographic factors, the amount of community variation was seriously reduced. Although the null model revealed substantive variation at the community level $(\rho=0.056)$, these community differences cannot be seen as evidence that communities matter because this could simply be due to individual composition. The proportion of variance on the contextual level in the second model indicates that the between community variations are clearly a consequence of the individual compositional differences rather than "true" contextual differences between communities $(\rho=0.016)$. However, this does not necessarily imply an absence of community effects. By not including the relevant community predictors, we could mis-specify the fixed part of a two-level statistical model (Subramanian et al., 2002). Model 4 introduces the objective community measures which are both significant $(p<0.05)$. Average income is negatively related to perceived health; higher SES communities tend to have lower levels of perceived health. This should mean that the effect of individual socioeconomic position is substantially different from the effect of the community that you live in. The objective social capital measure's effect is more intuitive. Higher levels of traditional community social capital are linearly and positively associated with the perceived health and well-being of that community's inhabitants. However, below we discuss several reasons for treating this evidence with caution. Model 5a considers social capital at the community level, without controlling for individual social capital. Although community social capital is positively related to perceived health and well-being $(p<0.01)$, it does not explain away the relationship between family affluence and perceived health. Model 5b investigates social capital's possible differential effect by including social capital at the community level, as well as at the individual level. It seems that individual and community social capital produce additive effects on perceived health. But, community social capital is a much stronger predictor for health $(B=0.314$, $\mathrm{SE}=0.039)$, than individual social capital $(B=0.019, \mathrm{SE}=0.006)$. The final model examines a cross-level interaction between social capital at the community level and family affluence at the

Table 2

Fixed and random parameters of the perceived health and well-being model.

\begin{tabular}{|c|c|c|c|c|c|c|c|}
\hline & Model 1 & Model 2 & Model 3 & Model 4 & Model 5a & Model 5b & Model 6 \\
\hline \multicolumn{8}{|l|}{ Fixed effects } \\
\hline Constant & $3.844(0.010)^{* * *}$ & $3.940(0.009)^{* * *}$ & $3.938(0.009)^{* * *}$ & $3.946(0.009)^{* * *}$ & $3.946(0.008)^{* * *}$ & $3.947(0.009)^{* * *}$ & $3.951(0.009)^{* * *}$ \\
\hline \multicolumn{8}{|l|}{ Level 1} \\
\hline Girl & & $-0.144(0.011)^{* *}$ & $-0.134(0.011)^{* *}$ & $-0.137(0.011)^{* *}$ & $-0.137(0.011)^{* *}$ & $-0.135(0.011)^{* *}$ & $-0.140(0.013)^{* *}$ \\
\hline Age & & $-0.074(0.002)^{* * *}$ & $-0.072(0.002)^{* * *}$ & $-0.071(0.002)^{* * *}$ & $-0.068(0.002)^{* * *}$ & $-0.068(0.002)^{* * *}$ & $-0.068(0.002)^{* * *}$ \\
\hline Family affluence & & & $0.023(0.003)^{* *}$ & $0.021(0.003)^{* *}$ & $0.021(0.003)^{* *}$ & $0.020(0.003)^{* *}$ & $0.021(0.003)^{* *}$ \\
\hline Individual social capital & & & $0.018(0.006)^{* *}$ & $0.020(0.006)^{* *}$ & - & $0.019(0.006)^{* *}$ & $0.018(0.006)^{* *}$ \\
\hline \multicolumn{8}{|l|}{ Level 2} \\
\hline Average income & & & & $-0.007(0.003)^{*}$ & $-0.010(0.003)^{* *}$ & $-0.010(0.003)^{* *}$ & $-0.011(0.003)^{* *}$ \\
\hline Traditional social capital & & & & $0.020(0.006)^{* *}$ & $0.015(0.005)^{* *}$ & $0.014(0.005)^{* *}$ & $0.015(0.005)^{* *}$ \\
\hline Community social capital & & & & & $0.309(0.038)^{* *}$ & $0.314(0.039)^{* *}$ & $0.317(0.039)^{* *}$ \\
\hline \multicolumn{8}{|l|}{ Level 1/Level 2 interaction } \\
\hline $\begin{array}{l}\text { Family affluence } \times \\
\text { community } \\
\text { social capital }\end{array}$ & & & & & & & $-0.034(0.017)^{*}$ \\
\hline \multicolumn{8}{|l|}{ Random effects } \\
\hline \multicolumn{8}{|l|}{ Level 1} \\
\hline Constant & $0.334(0.005)^{* * *}$ & $0.308(0.004)^{* * *}$ & $0.303(0.004)^{* * *}$ & $0.301(0.004)^{* * *}$ & $0.302(0.004)^{* * * *}$ & $0.301(0.004)^{* * * *}$ & $0.299(0.004)^{* * *}$ \\
\hline \multicolumn{8}{|l|}{ Level 2} \\
\hline Constant & $0.020(0.003)^{* *}$ & $0.005(0.001)^{* *}$ & $0.006(0.001)^{* *}$ & $0.005(0.001)^{* *}$ & $0.002(0.001)^{*}$ & $0.002(0.001)^{*}$ & $0.005(0.002)^{*}$ \\
\hline Girl & & & & & & & $0.010(0.004)^{*}$ \\
\hline Girl/constant & & & & & & & $-0.005(0.002)^{*}$ \\
\hline Log likelihood & 19340.030 & 18180.467 & 16728.438 & 16122.893 & 16638.848 & 16063.307 & 16050.005 \\
\hline$\Delta$ Log likelihood $(\Delta \mathrm{df})$ & & $1159.563(2)$ & $1452.029(2)$ & $605.545(2)$ & & $59.586(1)$ & $13.302(1)$ \\
\hline$p$ & & $<0.001$ & $<0.001$ & $<0.001$ & & $<0.001$ & $<0.001$ \\
\hline
\end{tabular}

${ }^{*} p<0.05,{ }^{* *} p<0.01,{ }^{* * *} p<0.001 ; \rho$ null model $=5.6 \% ; \rho$ model $2=1.6 \%$. 
individual level $(p<0.05)$. Only a small proportion of the variance in health can still be found at the community level in the final model. Fig. 1 plots the predicted relationship between family affluence and perceived health, for low and high social capital communities. Simple slope analysis revealed some important findings: (i) The social gradient in perceived health and well-being was flattened in communities with a high level of community social capital and consequently (ii) the SES differences in perceived health and well-being narrow in high social capital communities.

A further examination of this complex cross-level interaction following the Aiken \& West (1996) procedure (results not shown) reveals that the SES differences in perceived health and wellbeing substantially narrow in communities where a certain (average) level of community social capital is present (Fig. 2). So, the observed ceiling effect of community social capital generates 'diminishing returns': one unit of increase in community social capital does not produce a constant increase in perceived health and well-being for all children in that community. In particular, individuals living in communities with a low level of community social capital will benefit from an increase in community social capital, while individuals living in communities with an average level of community social capital receive only small perceived health and well-being benefits from a similar increase in community social capital.

\section{Discussion}

This study analyzed the compositional and contextual sources of variation in perceived health and well-being across 601 Flemish communities sampled in the 2005-2006 Health Behaviour in School-aged Children study. More specifically, this study investigated whether community social capital can 'level up' the gradient in health. The multilevel statistical framework provided us with a clue about the influence of community contexts in shaping health patterns. At the individual level, the socio-demographic variables were significantly associated with the dependent: girls and older adolescents reported lower levels of perceived health. A social gradient was demonstrated for level 1 family affluence and perceived health. Strikingly, a reversed gradient was found for objective average income (level 2) and perceived health. However, there are several reasons why this evidence should be treated with caution. Firstly, income as an indicator for SES is biased in several ways (Demissie, Hanley, Menzies, Joseph, \& Ernst, 2000). Secondly, there were a lot of missing values on this variable. By putting income in the model,

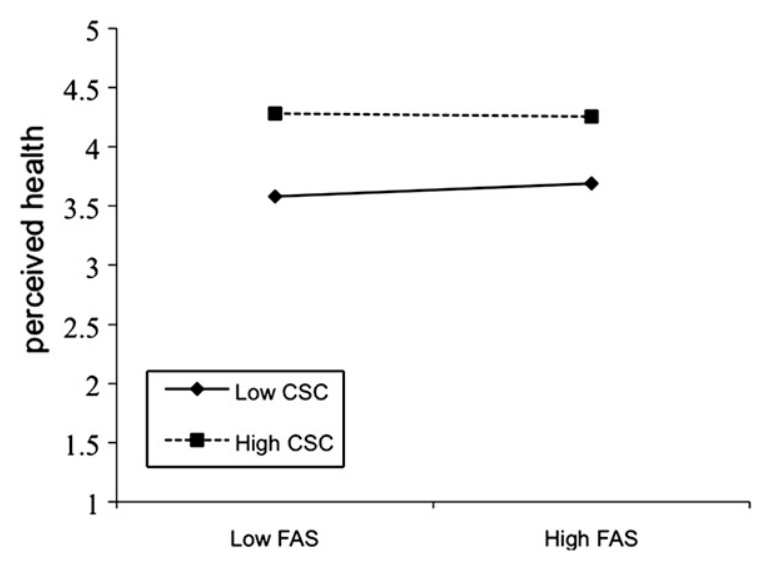

Fig. 1. Predicted relationship between family affluence (FAS) and perceived health and well-being, for low and high levels of community social capital (CSC) based on the fixed part results from Model $6(p<0.05)$.

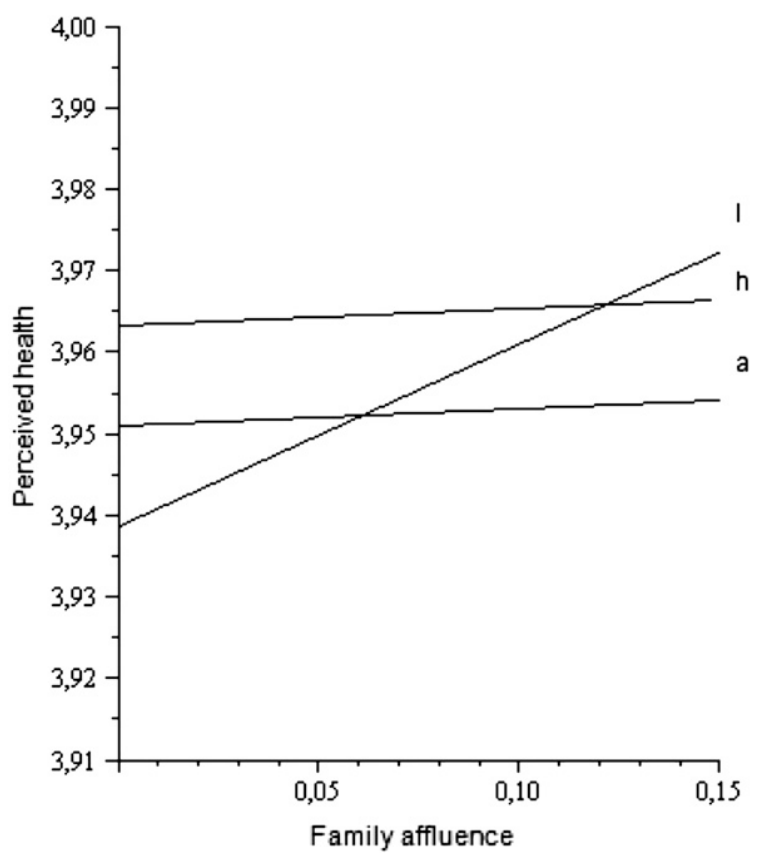

Fig. 2. Predicted relationship between family affluence and perceived health and wellbeing by community social capital (CSC) (l: low CSC, a: average CSC and h: high CSC) based on the fixed part results from Model $6(p<0.05)$.

we lost 124 level 2 units. A third reason that also explains the substantial loss of variation is the fact that the objective data are collected on a larger scale than the self-reported HBSC data. Some of the 601 HBSC communities are covered by the same statistical sector from the objective data. This incapacity to match the data should be taken into account while interpreting the results of these objective measures. Consistent with Morgan and Haglund (2009), individual and community social capital produced additive effects on perceived health but community social capital is a much stronger predictor for health than individual social capital. In line with the social cohesion school of social capital, this evidence supports the community approach of the current study and emphasizes social capital's role as a collective resource for health. Traditional social capital (level 2) was also positively associated with perceived health. There was no evidence for a mediating pathway of community social capital as a protective factor for health. However, a statistically significant complex interaction effect was found, such that the social gradient in perceived health and well-being was flattened in communities with a high level of community social capital.

Our findings contribute to the empirical literature on social capital and health in four ways. First, controlling for individual compositional differences, our results reveal "true" contextual differences between communities. In contrast to other research (Poortinga, 2006; Portes, 1998; Subramanian et al., 2002; Veenstra, 2005), this evidence suggests that social capital operates both at the individual and the community level. The Dutch study of van der Linden et al. (2003) supports this evidence. They state that (i) there is accumulating evidence that the shared social environment at the neighborhood level exerts significant effects on health over and above individual level variables and (ii) that the effects of deprivation on children's health cannot be interpreted without taking into account the context of social capital. Other research also substantiates the notion of social capital as a truly contextual construct (Subramanian, Lochner et al., 2003). Following Kawachi et al. (2004), "the novel contribution of social capital lies in its 
collective dimension, i.e. its potential to account for group-level influences on individual health." The essential difference between the present study and the approach of Subramanian et al. (2002) and Poortinga (2006) is that we see individual and community social capital as qualitative distinguishable constructs with a different substantial meaning. Individual social capital reflects an individual's personal network, whereas community social capital covers a broader sense of social neighborhood quality. Therefore, we included different items on both levels to measure individual and community social capital instead of using an identical social capital scale on both levels. Subramanian, Lochner et al. (2003) emphasize that caution and sound theory should inform the use of adjusted contextual measures (e.g. Subramanian et al., 2002). Adjusting a contextual measure for individual compositional factors may end up obscuring important place differences. On the other hand, it makes sense to include the same items on both levels when there are reasons to suspect confusion between compositional and contextual variation. Second, this study provides more information about which level (social or geographical) social capital operates. Unlike other studies that focused on the national (Poortinga, 2006) or US state level (Kawachi et al., 1999), the current study focuses on the community level, which is a smaller geographical and social unit. This might be an important reason why other studies failed to find contextual effects. Third, the important empirical finding that social capital is a mechanism that explains health inequalities confirms Wilkinson's (1996) hypothesis. Fourth, this study performed a specific examination of the complex cross-level interaction between individual socioeconomic status and community social capital. We found that (i) the linear relationship between socioeconomic status and health ("the social gradient") is flattened in communities with a high level of community social capital and that (ii) this mechanism operates as a ceiling effect so that investments in community social capital have diminishing returns. Therefore, policymakers should target neighborhoods with low levels of community social capital.

\section{Strengths}

A first strength of this study is the large number of level 2 units $(n=601)$, which provides us enough power to detect more subtle community processes. The Maximum Likelihood (ML) estimation method used in this paper is asymptotic, which translates to the assumption that the sample size must be sufficiently large. A simulation study indicated that the standard errors of the second-level variances are estimated as too small when the number of groups is substantially lower than 100 (Maas \& Hox, 2005). This could be the reason why studies like Poortinga (2006) with a small level 2 sample size of 22, failed to pick up subtle contextual effects. Secondly, we used different items as indicator for individual and community social capital. By using multiple indicators of community- and individual level social capital, we were able to perform a detailed assessment and meaningful interpretation of their effects. A third strength of this study is the use of advanced multilevel techniques in this matter. Subramanian et al. (2002) urge the routine consideration of the cross-level nature of community or neighborhood effects in future multilevel investigations on social capital and population health. Furthermore, this study also performed a detailed estimation of the random part of the model. Much of the existing application of multilevel research continues to focus largely on the fixed part of the model, rather than both the fixed and the random part. Subramanian (2004) sees this as a critical issue and a challenge to multilevel statistical methods for identifying causal neighborhood effects because the dual focus is completely lacking in the current applications.

\section{Limitations}

A general obstacle of two-level hierarchical multilevel models of the kind estimated in this research is the problem of endogeneity (Kawachi \& Subramanian, 2007). Neighborhood effects are never independent (exogenous) from the people who live in the neighborhoods: there is an inevitable selection process of individuals in terms of where they choose to live. Since the data are crosssectional, we cannot exclude reverse causation, i.e. the possibility that worse perceived health and well-being leads to the erosion of community social capital. However, note that the study sample comprises pupils and not adults. Children are less mobile and have less control over the neighborhoods they live in than adults (e.g. moving to another neighborhood a result of an existing health problem) and they may suffer from different health problems than adults living in the same community. Therefore it is likely that the pupil sample in this study is less susceptible to endogeneity than a random sample of adults. Endogeneity can also occur due to the presence of unobserved common prior causes of neighborhood level exposures and health outcomes (confounding). For example, a neighborhood watch organization within a community acts as a protective factor for residents' mental health. However, the decision to create such a social structure is a response to residents' feelings of safety. In this case, feelings of safety is an unobserved variable related to both the occurrence of a neighborhood watch organization and people's mental health. Oakes (2004) is rather pessimistic in this respect, claiming that any attempt to separate out the "independent" effects of neighborhood characteristics and individual level indicators is futile because the former is endogenous to the latter. In a commentary, Diez Roux (2004) argues that Oakes' conclusion was based on a specific situations (in accordance with Manski's (1995) definitions of endogenous effects) where the average dependent variable for a group (or community) is included as a predictor of individual level outcomes. But this situation, in which a researcher attempts to differentiate between endogenous, contextual, and individual level (or other group effects) is not typical of neighborhood effects research to date. However, Oakes' argument is valuable in pointing out the complexities of the problem. Endogeneity is partially tractable by means of the application of innovative multilevel structures (Subramanian, 2004). The principle is that we map the amount of influence (i.e. time) individuals are exposed to in the different communities they live in. Such a "repeated measure, multiple membership" design allows an estimation of changing neighborhood effects, controlling for the changing population composition and thus offer some progress in addressing the endogeneity in neighborhood exposures. Alternatively, researchers could overcome this limitation by using instrumental variable estimation (Glymour, 2006). The idea is to adjust models for the endogenous explanatory variables by finding "instrumental variables" that are (a) uncorrelated with the error term and (b) correlated strongly with the explanatory variables (Newhouse \& McClellan, 1998). Second, individual social capital (measured by membership in organizations) represents only the frequency of involvement with no sense of the quality of relationships or their benefits for the wider community. The idea is that an individual with only one friend who is a doctor will possess more potential health resources than someone with a large network of drug addicts. Third, this study used average income as a measure of community affluence. Regardless the large number of missing values, it has been criticized substantially since it might not be income but income inequality that is more important for health in rich countries (Kawachi \& Kennedy, 1998; Wilkinson, 1996, 1997). It would be interesting to include more information about the dispersion of income within a geographical unit. The argument is that high levels of income inequality are associated with low levels 
level 2: neighborhood
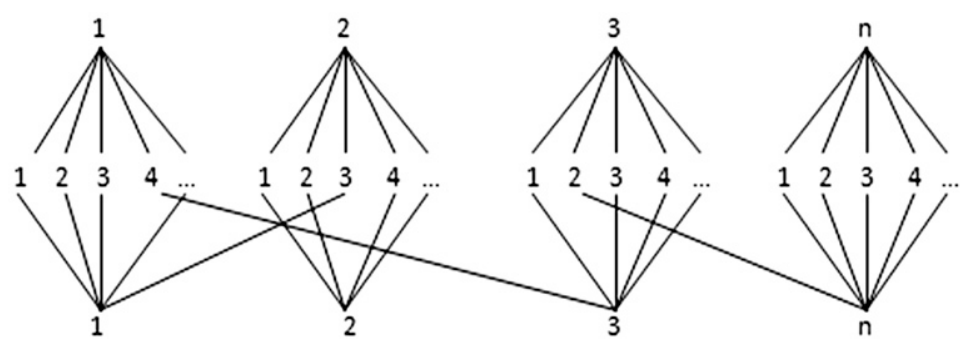

level 2: school

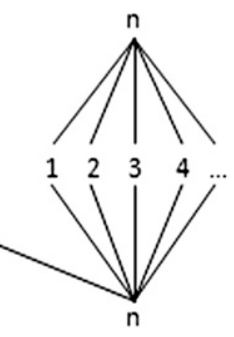

Fig. 3. Cross-classified multilevel structure of individuals nested within schools and neighborhoods.

of social support and cohesion and so sicken everyone, rich and poor alike. Note that within the research on income inequality, there is an ongoing debate between "neo-material" interpretations that focus on structural causes (Lynch, Davey Smith, Kaplan, \& House, 2000) and "psychosocial" interpretations that also emphasize the role of social relations and psychosocial well-being (Marmot \& Wilkinson, 2001). Fourth, it should be noted that the years of data collected from the children (HBSC 2005-2006 data) and the years of data collected at the community level (SCIF 2007-2011 data) do not overlap. However, this should not bias the results too much since community level indicators are relatively stable. And last, researchers have to be modest in their conclusions and interpretations. With this research we focus on community social capital as an important moderating factor for health. But, the underlying fundamental question is: What are the consequences of the organization of society and the changes in the organization of society for health and illness within the society?

Future research should use more complex multilevel models. The hierarchical scenario of individuals nested in neighborhoods is too simplistic. In the case of health outcomes, individuals' health status may be influenced both by where they live and where they go to school. Fig. 3 represents a cross-classified multilevel model where pupils are nested in schools and neighborhoods at the same time (Hox, 2002).

Models that integrate such a realistic complexity will improve our understanding of neighborhood effects. Given the complexity and size of cross-classified models, it is advisable to carry out preliminary analyses using standard multilevel models (like the present study), leaving out each of the cross-classified factors in turn (Hox, 2002). The simple 2-level model estimated in this study was a first but indispensible step towards a better understanding of the contextual effects of community social capital that reduce inequalities in children's and adolescents' health. The paper substantiates the importance of connecting the health of individuals to their meso socioeconomic context within a multilevel framework.

\section{Acknowledgments}

This research was carried out within the framework of the GRADIENT project (www.health-gradient.eu) coordinated by EuroHealthNet, and has received funding from the European Community (FP7 2007-2013) under grant agreement no 223252.

Health Behavior in School-aged Children (HBSC) is an international study carried out in collaboration with WHO/EURO. The International Coordinator of the 2005/2006 survey was Candace Currie, PhD and the Data Management Centre Manager was Oddrun Samdal, PhD. For details, see www.hbsc.org.

\section{References}

Adler, N. E., Boyce, T., Chesney, M. A., Cohen, S., Folkman, S., Kahn, R. L., et al. (1994). Socioeconomic status and health: the challenge of the gradient. American Psychologist, 49, 15-24.
Aiken, L. S., \& West, S. G. (Eds.). (1996). Multiple regression: Testing and interpreting interactions. Newburry Park (Calif.): Sage.

Andersen, A., Krølner, R., Currie, C., Dallago, L., Due, P., Richter, M., et al. (2008). High agreement on family affluence between children's and parents' reports: international study of 11-year-olds. Journal of Epidemiology E' Community Health, 62, 1092-1094.

Aneshensel, C. S., \& Sucoff, C. A. (1996). The neighborhood context of adolescent mental health. Journal of Health and Social Behavior, 37, 293-310.

Baum, F. E. (1999). Social capital: is it good for your health? Issues for a public health agenda. Journal of Epidemiology \& Community Health, 53, 195-196.

Berkman, L. F., \& Syme, S. L. (1979). Social networks, host resistance, and mortality: a nine-year follow-up study of Almeda country residents. American Journal of Epidemiology, 109, 186-204.

Botterman, S., \& Hooghe, M. (2010). The rural-urban divide in voluntary participation. A multilevel study of the impact of community indicators on membership of voluntary associations in Belgium. In International conference from GDP to well-being: Economics on the road to sustainability, Ancona, Italy.

Botterman, S., Hooghe, M., \& Reeskens, T. 'one size fits all'? an empirical study into the multidimensionality of social cohesion indicators in Belgian local communities. Urban Studies, in press, doi:10.1177/0042098010397397.

Bourdieu, P. (1986). The forms of capital. New York: Greenwood Press.

Boyce, W. F., Davies, D., Gallupe, O., \& Shelley, D. (2008). Adolescent risk taking, neighborhood social capital, and health. Journal of Adolescent Health, 43, $246-252$.

Coleman, J. S. (1988). Social capital in the creation of human capital. The American Journal of Sociology, 94, 95-120.

Currie, C., Elton, R. A., Todd, J., \& Platt, S. (1997). Indicators for socio-economic status for adolescents: the WHO Health Behaviour in School-aged Children Survey. Health Education Research, 12, 385-397.

Currie, C., Molcho, M., Boyce, W., Holstein, B., Torsheim, T., \& Richter, M. (2008). Researching health inequalities in adolescents: the development of the Health Behaviour in School-Aged Children (HBSC) family affluence scale. Social Science E Medicine, 66, 1429-1436.

Currie, C., Nic Gabhainn, S., Godeau, E., \& the International HBSC Network Coordinating Committee. (2009). The Health Behaviour in School-aged Children: WHO Collaborative Cross-National (HBSC) Study: origins, concept, history and development 1982-2008. International Journal of Public Health, 54, 131-139.

Currie, C., Nic Gabhainn, S., Godeau, E., Roberts, C., Smith, R., Currie, D., et al. (2008). Inequalities in young peoples health. Health behaviour in school aged children international report from the 2005/6 survey. Copenhagen: WHO.

Currie, C., Samdal, O., Boyce, W., \& Smith, R. (2001). Health behaviour in school-aged children: A WHO cross-national study (HBSC), research protocol for the 2001/2002 survey. Edinburgh: Child and Adolescent Health Research Unit (CAHRU), University of Edinburgh.

Demissie, K., Hanley, J. A., Menzies, D., Joseph, L., \& Ernst, P. (2000). Agreement in measuring socio-economic status: area-based versus individual measures. Chronic Diseases in Canada, 21,1-7.

Diez Roux, A. V. (1998). Bringing context back into epidemiology: variables and fallacies in multilevel analysis. American Journal of Public Health, 88, 216-222.

Diez Roux, A. V. (2001). Investigating neighborhood and area effects on health. American Journal of Public Health, 91, 1783-1789.

Diez Roux, A. V. (2002). A glossary for multilevel analysis. Journal of Epidemiology \& Community Health, 56, 588-594.

Diez Roux, A. V. (2004). Estimating neighborhood health effects: the challenges of causal inference in a complex world. Social Science $\mathcal{E}$ Medicine, 58, 1953-1960.

Drukker, M., Kaplan, C., Feron, F., \& van Os, J. (2003). Children's health-related quality of life, neighborhood socio-economic deprivation and social capital. A contextual analysis. Social Science $\mathcal{E}$ Medicine, 57, 825-841.

Duncan, C., Jones, K., \& Moon, G. (1998). Context, composition and heterogeneity: using multilevel models in health research. Social Science \& Medicine, $1,97-117$.

Ellen, I. G., Mijanovich, T., \& Dillman, K.-N. (2001). Neighborhood effects on health: exploring the links and assessing the evidence. Journal of Urban Affairs, 23, 391-408.

Erhart, M., Ottova, V., Gaspar, T., Jericek, H., Schnohr, C., Alikasifoglu, M., et al. (2009). Measuring mental health and well-being of school-children in 15 European countries using the KIDSCREEN-10 index. International Journal of Public Health, 54, 160-166. 
Folland, S. (2007). Does "community social capital" contribute to population health? Social Science \& Medicine, 64, 2342-2354.

Frumkin, H. (2003). Healthy places: exploring the evidence. American Journal of Public Health, 93, 1451-1456.

Glymour, M. (2006). Natural experiments and instrumental variables analyses in social epidemiology. In M. Oakes, \& J. S. Kaufman (Eds.), Methods in social epidemiology. New York: Jossey-Bass/Wiley.

Goldstein, H. (2003). Multilevel statistical models (3rd ed.). London: Hodder Arnold. Hawe, P., \& Schiell, A. (2000). Social capital and health promotion: a review. Socia Science \& Medicine, 51, 871-885.

Hemingway, H., \& Marmot, M. (1999). Psychosocial factors in the aetiology and prognosis of coronary heart disease: systematic review of prospective cohort studies. BMJ, 318, 1460-1467.

House, J. S., Landis, K. R., \& Umberson, D. (1988). Social relationships and health. Science, 241, 540-545.

Hox, J. (2002). Multilevel analysis: Techniques and applications. New York Psychology Press. Taylor and Francis Group.

Kawachi, I. (2006). Commentary: social capital and health - making the connections one step at the time. International Journal of Epidemiology, 35, 989-993.

Kawachi, I., \& Berkman, L. F. (2000). Social cohesion, social capital and health. In L. F. Berkman, \& I. Kawachi (Eds.), Social epidemiology. New York: Oxford University Press.

Kawachi, I., \& Kennedy, B. P. (1998). Income inequality and health: pathways and mechanisms. Health Services Research, 34, 215-227.

Kawachi, I., Kennedy, B. P., \& Glass, R. (1999). Social capital and self-rated health: a contextual analysis. American Journal of Public Health, 89, 1187-1193.

Kawachi, I., Kennedy, B. P., Lochner, K., \& Prothow-Stith, D. (1997). Social capital, social inequality, and mortality. American Journal of Public Health, 87, 1491-1498.

Kawachi, I., Kim, D., Coutts, A., \& Subramanian, S. V. (2004). Commentary: reconciling the tree accounts of social capital. International Journal of Epidemiology, $33,682-690$.

Kawachi, I., \& Subramanian, S. V. (2007). Neighbourhood influences on health. Journal of Epidemiology \& Community Health, 61, 3-4.

Kawachi, I., Subramanian, S. V., \& Almeida-Filho, N. (2002). A glossary for health inequalities. Journal of Epidemiology \& Community Health, 56, 647-652.

Kawachi, I., Subramanian, S. V., \& Kim, D. (2008). Social capital and health: a decade of progress and beyond. In I. Kawachi, S. V. Subramanian, \& D. Kim (Eds.), Social capital and health (pp. 1-26). New York: Springer.

Lin, N. (1999). Building a network theory of social capital. Connections, 22, 28-51.

van der Linden, J., Drukker, M., Gunther, N., Feron, F. \& van Os, J. (2003). Children's mental health service use, neighborhood socioeconomic deprivation, and social capital. Social Psychiatry Psychiatric Epidemiology, 38, 507-514.

Lynch, J., Davey Smith, G., Kaplan, G. A., \& House, J. S. (2000). Income inequality and mortality: importance to health of individual income, psychosocial environment, or material conditions. BMJ, 320, 1200-1204.

Lynch, J., Due, P., Muntaner, C., \& Davey Smith, G. (2000). Social capital - is it a good investment strategy for public health? Journal of Epidemiology \& Community Health, 54, 404-408.

Maas, C., \& Hox, J. (2005). Sufficient sample sizes for multilevel modeling. Methodology, 1, 86-92.

Macinko, J., \& Starfield, B. (2001). The utility of social capital in research on health determinants. The Milbank Quarterly, 79, 387-427.

Macintyre, S. (2000). The social patterning of health: bringing the social context back in. Medical Sociology Newsletter, 26, 14-19.

Macintyre, S., Ellaway, A., \& Cummins, S. (2002). Place effects on health: how can we conceptualise, operationalise and measure them? Social Science \& Medicine, 55, 125-139.

Manski, C. F. (1995). Identification problems in the social sciences. Cambridge, MA: Harvard University Press.

Marmot, M., Allen, J., Goldblatt, P., Boyce, T., McNeish, D., Grady, M., et al. (2010). Fair society, healthy lives: A strategic review of health inequalities in England post-2010. London: University College London.

Marmot, M., Friel, S., Bell, R., Houweling, T. A., \& Taylor, S. (2008). Closing the gap in a generation: health equity through action on the social determinants of health. Lancet, 372, 1661-1669.

Marmot, M., Stansfeld, S., Patel, C., North, F., Head, J., White, I., et al. (1991). Health inequalities among British civil servants: the Whitehall II study. The Lancet, 337 1387-1393

Marmot, M., \& Wilkinson, R. (2001). Psychosocial and material pathways in the relation between income and health: a response to Lynch et al. BMJ, 322, 1233-1236.

Mechanic, D. (1990). Promoting health. Society, 27(2), 16-22.

Morgan, A., \& Haglund, B. J. A. (2009). Social capital does matter for adolescent health: evidence from the English HBSC study. Health Promotion International, 24, 363-372.

Morgan, A., \& Ziglio, E. (2007). Revitalising the evidence base for public health: an assets model. Promotion and Education, 2007, 17-22.
Muntaner, C., \& Lynch, J. (1998). Income inequality and social cohesion versus class relations: a critique of Wilkinson's neo-Durkheimian research program. International Journal of Health Services, 29, 59-81.

Newhouse, J. P., \& McClellan, M. (1998). Econometrics in outcome research: the use of instrumental variables. Annual Review of Public Health, 19, 17-34.

O'Campo, P. J. (2003). Invited commentary: advancing theory and methods for multilevel models of residential neighborhoods and health. American Journal of Epidemiology, 157, 9-13.

Oakes, M. (2004). The (mis)estimation of neighborhood effects: causal inference for a practicable social epidemiology. Social Science $\mathcal{E}$ Medicine, 58, 1929-1952.

Pearce, N., \& Davey Smith, G. (2003). Is social capital the key to inequalities in health? American Journal of Public Health, 93, 122-129.

Pickett, K., \& Pearl, M. (2001). Multilevel analyses of neighborhood socioeconomic context and health outcomes: a critical review. Journal of Epidemiology $\mathcal{E}$ Community Health, 55, 111-122.

Poortinga, W. (2006). Social capital: an individual or collective resource for health? Social Science E' Medicine, 62, 292-302.

Portes, A. (1998). Social capital: its origins and applications in modern sociology Annual Review of Sociology, 24, 1-24.

Portes, A. (2000). The two meanings of social capital. Sociological Forum, 15, 1-12. Putnam, R. (1993). Making democracy work. Princeton: Princeton University Press.

Rasbash, J Steele, F. Browne, W. J. \& Goldstein, H. (2009). A user's guide to MLwiN, v2.1: Centre for multilevel modelling. University of Bristol.

Ravens-Sieberer, U., Erhart, M., Rajmil, L., Herdman, M., Auquier, P., Bruil, J., et al. (2010). Reliability, construct and criterion validity of the KIDSCREEN-10 score: a short measure for children and adolescents' well-being and health-related quality of life. Quality of Life Research, 19, 1487-1500.

Roberts, C., Currie, C., Samdal, O., Currie, D., Smith, R., \& Maes, L. (2007). Measuring the health and health behaviours of adolescents through cross-national survey research: recent developments in the Health Behavior in School-aged Children (HBSC) study. Journal of Public Health, 15, 179-186.

Robinson, W. S. (1950). Ecological correlations and the behaviour of individuals. American Sociological Review, 15.

Runyan, D. K., Hunter, W. M., Socolar, R. R. S., Amaya-Jackson, L., English, D. Landsverk, J., et al. (1998). Children who prosper in unfavorable environments: the relationship to social capital. Pediatrics, 101, 12-18.

Sampson, R. J., Raudenbush, S. W., \& Earls, F. (1997). Neighborhoods and violent crime: a multilevel study of collective efficacy. Science, 277, 918-924.

Scales, P. (1999). Reducing risks and building developmental assets: essentia actions for promoting adolescent health. The Journal of School Health, 69.

Stokols, D. (1996). Translating social ecological theory into guidelines for community health promotion. American Journal of Health Promotion, 10, 282-297.

Subramanian, S. V. (2004). The relevance of multilevel statistical methods for identifying causal neighborhoods effects. Social Science $\mathcal{E}$ Medicine, 58 1961-1967.

Subramanian, S. V., Jones, K., \& Duncan, C. (2003). Multilevel methods for public health research. In I. Kawachi, \& L. F. Berkman (Eds.), Neighborhoods and health (pp. 65-111). New York: Oxford University Press.

Subramanian, S. V., \& Kawachi, I. (2004). Income inequality and health: what have we learned so far? Epidemiologic Reviews, 26, 78-91.

Subramanian, S. V., Kawachi, I., \& Kennedy, B. P. (2001). Does the state you live in make a difference? Multilevel analysis of self-related health in the US. Socia Science \& Medicine, 53, 9-19.

Subramanian, S. V., Kim, D., \& Kawachi, I. (2002). Social trust and self-rated health in US communities: a multilevel analysis. Journal of Urban Health: Bulletin of the New York Academy of Medicine, 79, 21-34.

Subramanian, S. V., Lochner, K., \& Kawachi, I. (2003). Neighborhood differences in social capital: a compositional artifact or a contextual construct? Health \& Place, $9,33-44$

Veenstra, G. (2005). Location, location, location: contextual and compositional health effects of social capital in British Columbia, Canada. Social Science $\mathcal{E}$ Medicine, 60, 2059-2071.

Vyncke, V., Stevens, V., De Clercq, B., Ieven, A., Hrafn Jonsson, S., Darias Curvo, S., et al. Does community social capital make a difference for levelling the health gradient in children? A literature review, submitted for publication.

Waterson, T., Alperstein, G., \& Stewart Brown, S. (2004). Social capital: a key factor in child health inequalities. Archives of Disease in Childhood, 89, 456-459.

Wilkinson, R. G. (Ed.). (1996). Unhealthy societies. The afflications of inequality. London/New York: Routledge.

Wilkinson, R. G. (1997). Socioeconomic determinants of health. Health inequalities: relative or absolute material standards? British Medical Journal, 314, 591-594.

Wilkinson, R. G. (2000). Inequality and the social environment: a reply to Lynch et al. Journal of Epidemiology \& Community Health, 54, 411-413.

Ziersch, A. M. Baum, F. E. MacDougall, C., \& Putland, C. (2005). Neighborhood life and social capital: the implications for health. Social Science E' Medicine, 60 , $71-86$. 